\title{
Question-answer pairs: the help of LSF
}

\author{
Charlotte Hauser (Université Paris Diderot, LLF, IJN) \\ charlotte.hauser@live.fr
}

\begin{abstract}
A growing literature has emerged on sign languages describing a particular construction which looks like a question followed by its fragment answer, but which crucially is not interpreted as such. In sign language litterature, it has successively been referred to as pseudoclefts (Wilbur 1996, Branchini 2014), rhetorical questions (Hoza et al. 1997), question-answer constituents (Davidson, Caponigro, and Mayberry 2008), or, more recently, Question Answer Pairs (QAP) in Kimmelman and Vink (2017). This last work proposes the existence of a grammaticalization process starting with information seeking questions and ending with question-answer constituent, creating a bridge between two of the main analyses proposed. In our article, we extend the bridge to Wilbur's analysis and beyond. We demonstrate, based on an extensive depiction of French Sign Language's (LSF) QAP properties, that the grammaticalization scale proposed in Kimmelman and Vink (2017) has to be further developed to integrate pseudoclefts as its ending point. Through morpho-phonetic, syntactic and semantic evidences, we will show that LSF instantiates a construction which is syntactically closer to pseudoclefts than American Sign Language and Sign Language of the Netherlands but not yet at the point of Italian Sign Language (Branchini 2014), advocating in favor of an intermediate analysis.
\end{abstract}

Keywords: LSF, pseudoclefts, rhetorical questions, grammaticalization process

\section{Short state of the art}

The construction in which the signer puts side by side a question and its answer as illustrated in ASL in example (1) goes under many names; from rhetorical questions (Hoza et al. 1997) to pseudoclefts (Wilbur 1996, Branchini 2014) depending on authors and analyses. We use, from now on, the most recent name "Question Answer Pairs" (QAP) (Kimmelman and Vink 2017) as a purely descriptive term to refer to any kind of construction superficially displaying these properties.

(1) [Q-constituent $\left.\frac{\mathrm{br}}{\text { JOHN BUY WHAT }}\right],[$ [a-constituent BOOK ] 'What John bought is a book.'

(Caponigro and Davidson 2011)

As for American Sign Language (ASL) three different analyses have been proposed, varying on the type and number of clauses that are claimed to be involved in the construction. The main features of the analyses are summarized in Table 1. 
Table 1: Analyses of question-answer pairs in ASL.

\begin{tabular}{|l|c|l|l|}
\hline Author(s) & Number of clauses & $\begin{array}{l}\text { Nature of the ques- } \\
\text { tion constituent }\end{array}$ & $\begin{array}{l}\text { Nature of the an- } \\
\text { swer constituent }\end{array}$ \\
\hline Hoza et al. 1997 & 2 & matrix question & matrix clause \\
\hline Wilbur 1996 & 1 & wh-cleft & small clause \\
\hline $\begin{array}{l}\text { Caponigro and } \\
\text { Davidson 2011 }\end{array}$ & 1 & embedded question & embedded clause \\
\hline
\end{tabular}

In their corpus study on Sign Language of the Netherlands (NGT), Kimmelman and Vink (2017) highlight the coexistence of different forms of question-answer pairs (QAP), some surfacing as two clauses and others as one single clause. This finding leads the authors to postulate the existence of a grammaticalization process actually at play in NGT and in ASL by which two separate clauses eventually get merged into one undergoing morphophonological and semantic transformations (see Figure 1).

Figure 1: Grammaticalization process, Kimmelman and Vink (2017)

$$
\left(\text { regular question } \rightarrow \text { ) } \begin{array}{l}
\text { rhetorical ques- } \\
\text { tion }
\end{array} \rightarrow \begin{array}{l}
\text { discourse-level } \\
\text { question-answer } \\
\text { combination }
\end{array} \rightarrow \begin{array}{l}
\text { question-answer } \\
\text { clause }
\end{array}\right.
$$

Through the corpus study of NGT, the authors argue against the extension of the grammaticalization process to pseudoclefts based on the observation that "even the clearly grammaticalized QAP show some properties that are incompatible with the wh-cleft analysis" (Kimmelman and Vink 2017, p. 440). The data we obtained in French Sign Language (LSF), along with Branchini (2014)'s work on Italian Sign Language (LIS), point towards the opposite as we will now demonstrate by offering detailed description of the properties of the QAP in French Sign Language (LSF).

\section{Question-Answer Pairs in LSF}

\subsection{Methodology}

We report data elicited from three consultants, all native signers of LSF. ${ }^{1}$ They were two men, Thomas Lévêque and Yohan Marcelino, and a woman, Laurène Loctin, all aged between 28 and 29. Thomas comes from the South West of France, Yohan from the North West and Laurène from the region of Paris. They all regularly collaborate with our research group as LSF consultants.

As QAP are frequent in LSF we started the elicitation by showing examples taken from Internet videos so that our informants could identify the structure we were interested in. After

\footnotetext{
${ }^{1}$ We call 'native' Deaf people born from at least one Deaf parent.
} 
confirming, through acceptability and felicity judgments, that the QAP were not interpreted as questions, we collected data in two steps using various fieldwork techniques. First, we obtained natural baselines through elicitation tasks (Stegenwallner-Schütz, Haendler, and Adani 2014; Belletti and Guasti 2015) asking to describe a picture in three ways: through a simple sentence, a QAP and a question. This step allowed us to identify the morphophonological differences between all structures.

In a second step, we started syntactic and semantic investigations using tests described in the literature to shed light on constituency, predication and referentiality (Wilbur 1996, Davidson, Caponigro, and Mayberry 2008, Hoza et al. 1997, Stickles 2013, Caponigro and Davidson 2011, Den Dikken 2007) as is described through this article in each related part.

\subsection{Morpho-phonetic properties}

As observed in ASL and LIS, QAP in LSF do not display the morpho-phonetic properties of questions. Indeed both rhetorical (2b) and information-seeking questions (2a) are signed with the eyebrows furrowed. On the other hand, QAP are realized with raised eyebrows and chin (see (2c)). These non-manual markers (NMM) are most of the time restricted to the whword, but depending on the signer, they can spread on the whole question constituent as shown in Figure 2. It should also be noted that the answer-constituent in QAP can optionally be introduced by a sign glossed as PALM-UP which doesn't have a precise translation but resemble 'well', a filler. Finally, although we do observe polar question/answer sequences in spontaneous speech (see (3)), we follow Wilbur (1996) in excluding them from the QAP group on interpretive grounds. Indeed, these constructions are really similar to those rhetorical questions that can be used in spoken French and English and are interpreted as a sort of exclamative expressions denoting surprise or shock.

(2) a. $\frac{\text { bf }}{\text { WHO OFFER FLOWER GIRL }}$

Wh.Qu.

'Who offered flowers to the girl ?'

$R h \cdot Q u$

b. WHO EAT CANDY? $\frac{\mathrm{bI}}{\mathrm{ME}} ? \frac{\mathrm{bI}}{\mathrm{NO}}$ !

'Who ates the candies (then)? Me? No!'

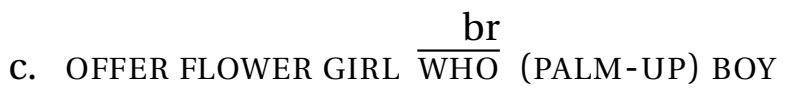

QAP

'The person whom offered flowers to the girl is, well, the boy.'

br

(3) $\overline{\text { IX-1 LAUGH}}$ ? NO!

'Me? Laughing? No (I wasn't)!' 
Figure 2: Spreading of the NMMs in Question-Answer Pairs. In (a), the NMMs associated to QAP are limited to the wh-word while in (b), they are spreading over the whole question constituent

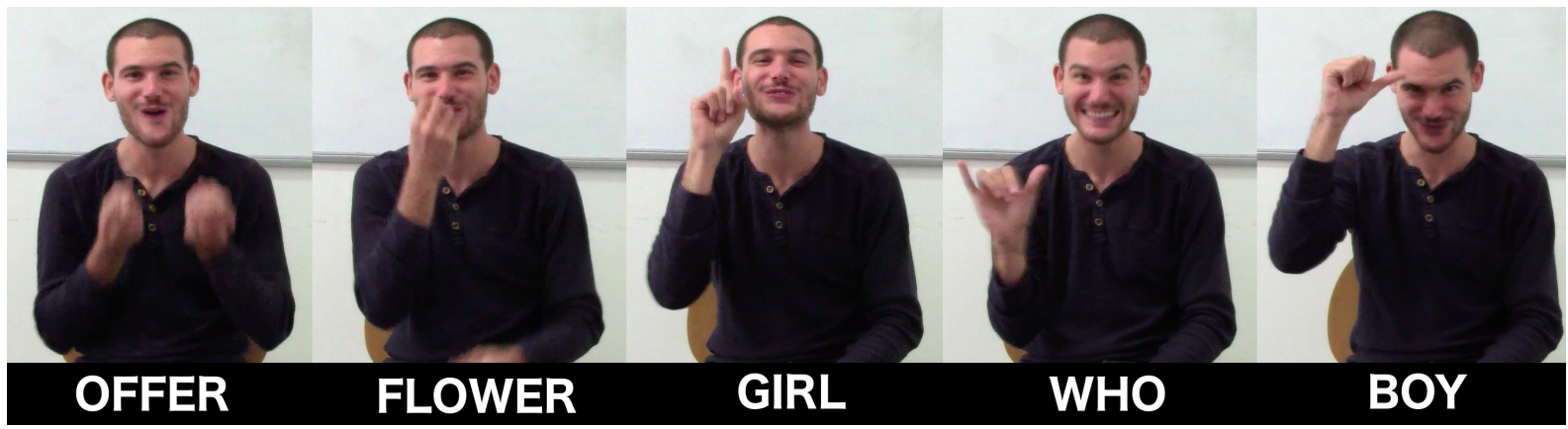

(a) 'The person whom offered flowers to the girl was the boy.'

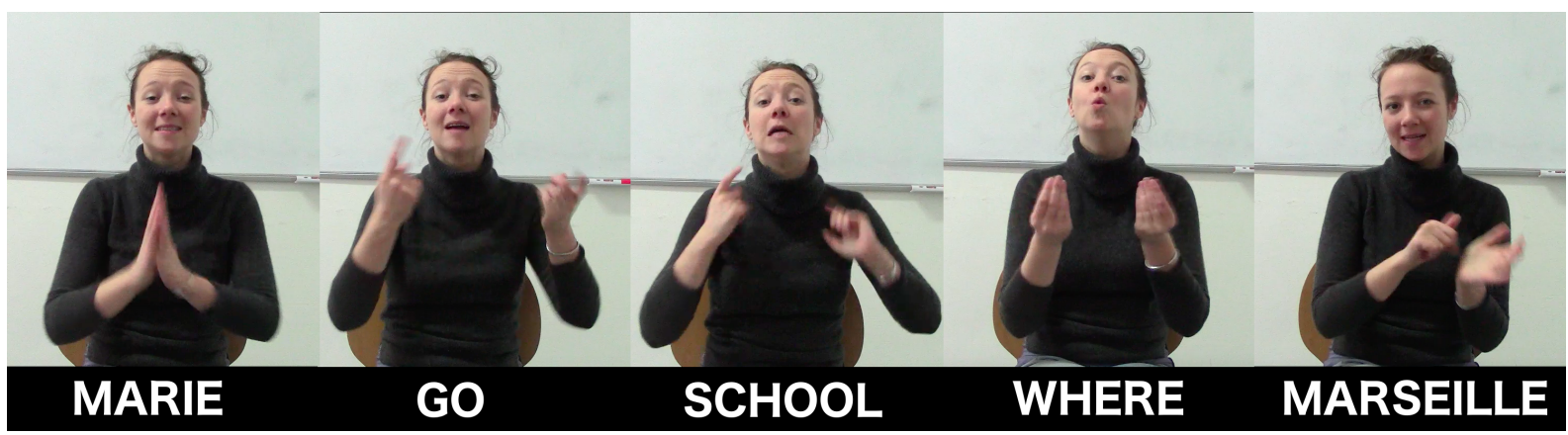

(b) 'Where Marie went to school was in Marseille.'

In order to go beyond the anecdotal observation and verify that NMMs actually distinguish questions and QAP, we conducted a preliminary study with our three informants using a discrimination task. We presented them 8 pairs of clipped QAP and questions. For QAP (4b), we cut the videos at the end of the wh-sign, before a transition movement could occur, removing the answer constituent. To avoid giving unwanted hints, we cut videos of questions making sure that the wh-signs (4a) had the same duration as in QAP. We then presented all the videos in randomized order, asking the informants to determine which were true questions. All of them performed at ceiling in the task, identifying all questions as being such. These results cannot be interpreted conclusively since more complex, controlled and representative experiments need to be conducted, but they seem to confirm the existence of two very different structures displaying distinct morpho-phonological properties.

(4) B. BOY OFFER FLOWER $\frac{\mathbf{b f}}{\mathrm{WHO}} \mid$
b. BOY OFFER FLOWER $\frac{\mathbf{b r}}{\mathrm{WHO}} \mid$ GIRL

Question

QAP

Finally, as in ASL, LIS and NGT, every wh-word normally available for questions can also be found in QAP. An example of each is presented in (5). An important remark has to be made regarding the use of the wh-word 'WHY' (see (5g)). Although it does appear in QAP, it is obligatorily followed by the PALM-UP sign. This might be due to the fact that, in LSF, WHY also translates as 'because' in declarative sentences such as (6). PALM-UP might be necessary in questions and QAP in order to disambiguate the 'why' vs. 'because' meanings. 
br

(5) a. BOY $i$ FLOWER OFFER $\overline{\text { WHO }}$ POSS $-3_{i}$ LOVER GIRL $^{2}$

'The person to whom the boy offers flowers is his girl fiancee.'

b. BOY OFFER GIRL $\frac{\text { br }}{\text { WHAT FLOWER }}$

'What the boy offers to the girl are flowers.'

br

c. MOM BOY PET $\overline{\text { WHERE }}$ FRONT TOWN-HALL

'Where the boy hugs his mom is in front of the town-hall.'

br

d. BOY ARRIVE SCHOOL $\overline{\text { HOW }}$ PALM-UP WALKING

'How the boy arrives to school is by walking.

br

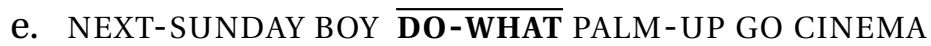

'What the boy is doing next Sunday is going to the cinema.'

br

f. MARY NOT-WANT BUY HOW-MANY THREE VASES .

'The number (of vases) that Mary does not want to buy is three vases.'

br

g. WOMAN PREPARE EAT INVITE DIRECTOR $\overline{\text { WHY, PALM-UP THEY-TWO DISCUSS PROJECT }}$ BIG FUTURE

'The woman is cooking, the reason why she invites the director is so the two of them can discuss their big project for the future.'

(6) MARIE $_{i}$ SICK WHY IX- $3_{i}$ FORGOT POSS $-3_{i}$ SCARF YESTERDAY

'Marie is sick because she forgot her scarf yesterday.'

With the description of the morpho-phonological properties of LSF QAP, we can conclude that QAP are very similar in the three sign languages under investigation: in all of them QAP do not include a proper question.

\subsection{Syntax}

As noted in Wilbur (1996) and Caponigro and Davidson (2011), the syntax of content questions and QAP differ. LSF patterns like the three other sign languages in this respect and this is first shown by the fact that the whole QAP can only be embedded under a verb taking non-interrogative clauses as its complement (see (7)). Following the reasoning of Caponigro and Davidson (2011), we reject the possibility for the 'answer' constituent of the QAP construction to involve direct speech quotation either since we do not observe either role shift or switching in the reference pattern when a pronominal is introduced (see (8)).

(7) JEAN HOPE /*ASK MARIE EAT WHAT STRAWBERRY

'Jean hopes that what Marie eats is a strawberry.'

\footnotetext{
${ }^{2}$ We use the indexical ' $i$ ' to express the semantic relatedness between a pronominal (either 'IX' for pointing pronouns or 'POss' for possessives) and its antecedent. This relationship is marked by the informants through the use of the signing space. In addition, the number which follows the pronominal element $(1,2$ or 3$)$ indicates whether it is a first, second or third person pronominal. Finally, following conventions established in Quer et al. (2017), text appearing on top of sentences indicates the presence of a set of non-manual markers whose scope is indicated through spreading of the line.
} 
(8) IX- $3_{i}$ PIERRE $_{i}$ HOPE JEAN $j$ BUY PRESENT FOR WHO POSS $-1_{* i / k}$ LOVER

Available: 'Pierre hopes that the person to whom Jean offers a gift is my (narrator's) girlfriend.'

Not Available: 'Pierre hopes: "the person to whom Jean offers a gift is his (Pierre's) girlfriend."'

Another clear piece of evidence for a syntactic difference comes from word order, and is specific to LSF. While the main strategy to create questions is in situ for both informationseeking and rhetorical questions (Geraci 2017) as shown in (2a) and (2b) in previous subsection, QAP require the wh-word to be at the right edge of the question clause (see (2c)). Following Cecchetto and Donati (2015), we believe that this obligatory movement serves a syntactic purpose. Due to space limitations we won't be able to develop fully the rationale presented in Cecchetto and Donati (2015) but we simply point to the fact that the authors directly relate obligatory overt wh-movement to the ambiguity displayed in many languages by wh-structures. As Caponigro (2003) has first pointed out, wh-structures with overt whmovement can be systematically ambiguous between a free-relative and a question.

As for both ASL and NGT, authors observe also different patterns between questions and QAP, but this is represented in the doubling pattern in the two constructions (the doubling is significantly less used or impossible in QAP while it is present in rhetorical questions). This could not be observed in LSF since doubling of the wh-word is barely used in content questions and in general. Lastly, in LIS, Branchini (2014) shows that the wh-word used in QAP cannot pied-pipe any material, differently from its indirect and matrix questions alternatives. This further tips the balance towards a pseudocleft analysis for this language.

Finally, an important property of QAP across sign languages which also holds for LSF is that the "question" and the "answer" cannot be inverted: this is shown in example (9).

(9) *BOOK JEAN BUY $\frac{\text { br }}{\text { WHAT }}$ Intended : 'A book is what Jean bought.'

This property, coupled with other observations, lead most authors to reject the possibility for QAP to be analyzed as pseudoclefts. ${ }^{3}$ Due to space limitation we will not be able to review in details the analyses of inverted pseudoclefts but Den Dikken, Meinunger, and Wilder (2000) argued that pseudoclefts and inverted pseudoclefts should not be considered as being equivalent since they display different semantic and syntactic properties. Therefore, the absence of the latter should not be taken as direct evidence for the lack of the former.

The syntactic and morpho-phonological features of LSF QAP are really close to their counterparts in ASL, LIS and NGT. While we do acknowledge the similarity between these constructions, we show now that LSF QAP also present some syntactic and semantic properties which single LSF out and discourage a unified account of the four languages.

\section{An intermediate step between QAC and pseudoclefts}

\subsection{Variations in syntax}

In their article about ASL, Hoza et al. (1997) notice that the equivalent of (10a), in which the negation only scopes over the predicate and not over the whole pseudocleft, is not possible

\footnotetext{
${ }^{3}$ Inversion and predication are not described in Branchini (2014) in relation to LIS.
} 
in ASL (10b). ${ }^{4}$ They conclude that ASL QAP cannot be analyzed as pseudoclefts since the copular structure of pseudoclefts must allow inflectional material (negation and/or tense markers) to intervene between the subject and the main clause predicate. Interestingly, in LSF, QAP do allow negation: a QAP more or less equivalent to (10a), namely (10c) is perfectly acceptable with the meaning of a pseudocleft construction.

(10) a. What Mary saw was not a book.
b. $* \frac{\mathrm{rh} / \mathrm{wh}}{\text { MARY SEE WHAT }}$ ? NOT BOOK (Hoza et al. 1997)
$\begin{array}{ll}\frac{\mathrm{br}}{\text { c. }} & \frac{\mathrm{neg}}{\mathrm{MARIE} \text { EAT WHAT ALMOND }} \\ \text { 'What Marie ate were not almonds.' }\end{array}$

ASL

In the same article, Hoza et al. (ibid) remark that QAP in ASL cannot be interrogated while this is possible with pseudoclefts in English (see (11a) and (11b)). They used this difference as a proof of the question-nature of QAP. In LSF, on the other hand, it is possible to interrogate a QAP: see (11c). This is clearly against an analysis of the LSF construction as including a question, even embedded (as proposed in Caponigro and Davidson (2011)), since questioning a question is not possible.

a. Was what Mary saw a book?

wh

b. * MARY SEE WHAT? BOOK

ASL

bf

(Hoza et al. 1997)

c. JEAN EAT $\frac{\text { br }}{\text { WHAT CHOCOLATE? }}$
'Was what Jean ate Chocolate?'

All in all, we observe clear syntactic differences between ASL QAP and LSF QAP. While QAP in ASL clearly differ from pseudoclefts of the English type for a number of properties, this is less true for LSF. For this reason the most recent analysis that has been proposed for ASL (Caponigro and Davidson 2011) cannot be extended to LSF since the "question constituent" is clearly different from a question from a syntactic point of view.

\subsection{Variations in semantics}

The semantics of QAP and pseudoclefts across languages is a complex topic. In the literature about spoken languages, the description of various semantics aspects (connectivity effects, referentiality and exhaustivity among others) lead to the recognition of different types of pseudoclefts, to be further classified into subtypes (see Den Dikken 2007 for a review). On the other hand, when it comes to sign languages, a semantic property that has been argued to distinguish pseudoclefts from questions is exhaustivity, namely the need for the answerclause to be the complete (hence exhaustive) list of correct answers to the discourse-level question.

\footnotetext{
${ }^{4}$ Personal discussions with ASL native signers brought to our knowledge that, in fact, this might also be possible in ASL contrary to what is said by the authors.
} 
As for ASL, Caponigro and Davidson (2011) argue that the difference between pseudoclefts and QAP lies in the optionality of this interpretation for the latter. According to the authors, pseudoclefts are obligatorily interpreted as being exhaustive while QAP exceptionally allow non-exhaustive answers.

In LSF, QAP are not exhaustive; the answer-constituent can be a sub-part of the possible answers available in the context. This is shown in (12) and (13) in which we replicated two tests proposed in Stickles (2013) to identify exhaustivity in ASL. In example (12), we see that the QAP cannot be refuted by a second signer on the pretext that it isn't exhaustive.

(12) Context: Marie bought chocolate, milk, coffee and a banana:

A: MARIE BUY WHAT MILK, CHOCOLATE COFFEE

'What Marie bought was milk, chocolate and coffee.'

B: \#NO, IX-2 MISTAKE, MARIE BUY ALSO BANANA

'No you're wrong ! Marie also bought a banana!'

As a second test, we observe that LSF allows the answer constituent to be made of an alsoclause (see 13) differently from ASL (Stickles 2013).

(13) JEANNE LIKE WHAT MUSIC ALSO

'What Jeanne likes is also music.'

In this respect, LSF QAP behaves neither like pseudoclefts nor like ASL QAP. However this criterion doesn't appear to be an optimal diagnostic since it is not valid crosslinguistically. While it holds for pseudoclefts in English, it does not hold, for instance, in French: in the dialogue in (14a) the reply of B is awkward; and the also-sentence in (14b) is possible.

a. Context: Marie bought chocolate and milk:

A: Ce que Marie a acheté c'est du chocolat.

'What Marie bought was chocolate.'

B: \# Non tu te trompes! Marie a aussi acheté du lait!

'No you're wrong ! Marie also bought milk!'

b. Ce que Marie aime c'est aussi la danse.

'What Marie likes is also dance.'

The results of this partial semantic survey confirm our conclusion that QAP in LSF and in ASL are different since the latter displays exhaustivity while the former doesn't. If exhaustivity is a property defining pseudoclefts over questions, QAP in LSF appear to be more distant from pseudoclefts than QAP in ASL: this seems to be at odds with the conclusion of the syntactic survey that points towards the opposite direction.

\subsection{Free-relatives, predication and referentiality}

Pseudoclefts in English involve a free-relative constituent. Yet Hoza et al. (1997), Caponigro and Davidson (2011) and Wilbur (1996) argue that ASL does not have free-relatives at all. It is indeed true that wh-words are never used in relative constructions in ASL but in LSF there is some evidence for a relative use of wh-words: this is displayed in example (15).

(15) $\frac{\text { br }}{\text { IX-2 CAN EAT WHAT PREFER }}$

'You can eat whatever (you) prefer.' 
Nonetheless, unlike their LIS counterparts (Branchini 2014), this construction appears to be severely restricted: in particular, the free-relative in (15) can only be interpreted nonreferentially. If we try to force its referentiality, as in (16), the result is ungrammatical.

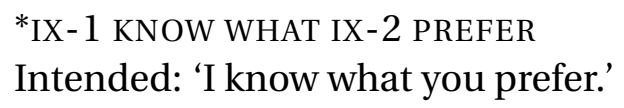

The contrast presented here is reminiscent of the distinction made in Grosu and Landman (1998) and De Vries (2002) between realis and irrealis free-relatives: while the former are DPs, the latter are identified by their CP nature and their lack of referentiality. A similar account could explain the asymmetry presented in example (17); while English allows both specificational (17a) and predicational pseudoclefts, ASL, NGT and LSF do not present the second type (17b). The impossibility to predicate over the "question" clause excludes the possibility to analyze it as being a DP-like element, as a realis free-relative would be.
a. MARIE EAT WHAT DESSERT
'What Marie ate was a dessert.'
b. *Marie eat What DELicious
'What Marie ate was delicious.'

Specificational

Predicational

Den Dikken, Meinunger, and Wilder (2000) argue that only predicational pseudoclefts involve DP free-relatives. As for specificational pseudoclefts, they are analyzed as a «hybrid [of free-relatives and embedded wh-questions] with both properties» (Den Dikken 2007), similarly to irrealis free-relatives in Grosu and Landman (1998)'s analysis. The availability of irrealis free-relatives of the type in example (16) is therefore consistent with the specificationalonly use of QAP in LSF. Both involve a structure that is closer to a CP, not a DP. ${ }^{5}$

\section{The grammaticalization process}

This brief comparison of QAP in LSF, ASL, LIS and NGT has clearly shown that in the four languages the construction cannot be equated to a rhetorical question strategy. In all four languages, the "question" constituent behaves differently from a proper question in a number of respects, with LIS constructions being maximally distant in allowing free-relatives of all kinds. LSF however emerges in exhibiting a QAP that is more distant from questions from a syntactic point of view than NGT and ASL, while not the step that LIS has reached. Given this state of affairs, it is only natural to suggest that there is a grammaticalization path leading from a purely rhetorical strategy to a proper (pseudo)clefting strategy, and that LSF is on the path between ASL, NGT and LIS. Kimmelman and Vink (2017) have made a very similar proposal on the base of the coexistence of different types of QAP in NGT. We extend their account to the cross-linguistic dimension.

The rationale of the proposal roots in Kimmelman and Vink (2017) and is schematized in Figure 3. Concretely, a rhetorical question and its answer start to be more and more used by signers as a focus strategy (step 1). The two clauses get linked at the discourse level (step 2) and start to be used as a new construction, being linked under a single clause (step 3) following Kimmelman and Vink (2017).

\footnotetext{
${ }^{5}$ Hoza et al. (1997) based on a possible interpretation of Iatridou and Varlokosta (1995) claim that, typologically, languages either display both predicational and specificational pseudoclefts or only predicational pseudocleft but never specificational pseudoclefts only. We are arguing on the contrary that this is a possibility and that LSF does instantiate it. We shall go back on this issue and the debate around it (see Frascarelli and Ramaglia 2013) in a future article.
} 
In step 4, what used to be a question then undergoes semantic and syntactic changes to become an irrealis free-relative, a hybrid between CP and DP which lacks truly nominal properties, explaining why it cannot be used referentially (Grosu and Landman 1998, De Vries 2002). In this step, the same wh-constituent becomes referential but is not yet fully nominalized (Faraci 1970, Den Dikken 2007 and Schlenker 2003). Finally, the wh-constituent is nominalized into a free-relative which can be used in a predicative copular construction (final step) ${ }^{6}$

Figure 3: Extended grammaticalization process

Step 1: Rhetorical question and its answer

Step 2: Discourse-level question/answer combination

Step 3: Question-Answer Clause

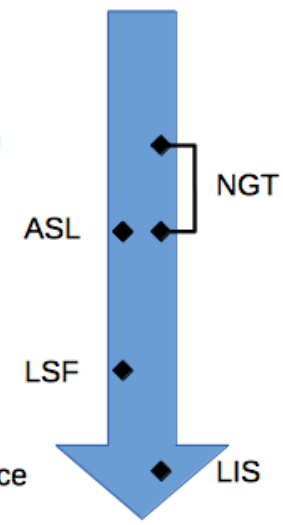

\section{Conclusion}

In this paper we have singled out a number of morpho-phonological, syntactic and semantic properties that all distinguish LSF QAP and their counterparts in ASL and NGT from questions. We used the forced movement of the wh-word and its presence in relative contexts as pieces of evidence teasing apart the construction in LSF from the other sign languages studied, locating it closer to pseudoclefts. However, other properties of the LSF QAP such as the impossibility to invert or predicate over the wh-clause and some differences regarding referentiality all converge in excluding that these constructions are properly pseudoclefts. This conclusion indicates the existence of an intermediate step between QAP in NGT and ASL and pseudoclefts in LIS and English.

We have described the relation existing between questions, QAP, LSF QAP and pseudoclefts in terms of a grammaticalization path, extending a similar proposal by Kimmelman and Vink (2017) on QAP in NGT but we still believe that this topic needs much further investigation. Indeed, the literature on pseudoclefts is rich in remarks associating questions, free-relatives and various types of cleft-sentences. A closer investigation into this literature and its empirical motivations could offer more ground to our hypothesis of a grammaticalization path. On the other hand, our work on LSF adds, together with parallel studies on other sign languages, another piece of evidence in favor of this strong association between questions and clefts.

\footnotetext{
${ }^{6}$ LIS seems to be at the final step since it has free-relatives, however, this has to be taken cautiously since, to the best of our knowledge, predication and inversion have not yet been studied.
} 


\section{References}

Belletti, Adriana, and Maria Teresa Guasti. 2015. The acquisition of Italian: morphosyntax and its interfaces in different modes of acquisition. Amsterdam: John Benjamins.

Branchini, Chiara. 2014. On relativization and clefting : An analysis of Italian Sign Language. Berlin: De Gruyter, Mouton.

Caponigro, Ivano. 2003. "Free not to ask: On the semantics of free relatives and wh-words cross-linguistically”. PhD thesis, University of California, Los Angeles.

Caponigro, Ivano, and Kathryn Davidson. 2011. "Ask, and tell as well: Question-Answer Clauses in American Sign Language”. Natural Language Semantics 19 (4): 323-371.

Cecchetto, Carlo, and Caterina Donati. 2015. On (re)labelling. Cambridge, MA: Cambridge University Press.

Davidson, Kathryn, Ivano Caponigro, and Rachel Mayberry. 2008. "Clausal Question-Answer Pairs: Evidence from ASL”. Proceedings of the West Coast Conference on Formal Linguistics 27:108-115.

De Vries, Mark. 2002. The syntax of relativization. Utrecht: LOT.

Den Dikken, Marcel. 2007. "Specificational copular sentences and pseudoclefts, A case study". In The Blackwell Companion to Syntax, ed. by M. Everaert and H. van Riemsdijk, 292-409. Wiley-Blackwell.

Den Dikken, Marcel, André Meinunger, and Chris Wilder. 2000. "Pseudoclefts and ellipsis". Studia Linguistica 1 (54): 41-89.

Faraci, Robert. 1970. “On the deep question of pseudo-clefts”. Manuscript, MIT.

Frascarelli, Mara, and Francesca Ramaglia. 2013. “(Pseudo)clefts at the syntax-prosody-discourse interface”. In Clefts structures, ed. by Katharina Hartmann and Tonjes Veenstra, 97-138. Amsterdam: John Benjamins.

Geraci, Carlo. 2017. “Description of French Sign Language phenomena”. Report of the SignHub Project (Deliverable 2.3.)

Grosu, Alexander, and Fred Landman. 1998. "Strange relatives of the third kind". Natural Language Semantics 6:125-170.

Hoza, Jack, Carol Neidle, Dawn MacLaughlin, Judy Kegl, and Benjamin Bahan. 1997. "A unified syntactic account of rhetorical questions in American Sign Language". In Syntactic structure and discourse function: An examination of two Constructions in American Sign Language. ASLLRP report No. 4, 2-23. Boston: ASLLRP.

Iatridou, Sabine, and S. Varlokosta. 1995. "Pseudoclefts crosslinguistically." Paper presented at NELS, Cambridge, MA.

Kimmelman, Vadim, and Lianne Vink. 2017. "Question-Answer Pairs in Sign Language of the Netherlands”. Sign Language Studies 17 (4): 417-449.

Quer, Josep, Carlo Cecchetto, Caterina Donati, Miriam Kelepir, Roland Pfau, and Markus Steinbach, eds. 2017. SignGram Blueprint. Berlin: De Gruyter Mouton.

Schlenker, Philippe. 2003. "Clausal equations (a note on the connectivity problem)". Natural Language and Linguistic Theory 21 (1): 157-214. 
Stegenwallner-Schütz, Maja, Yair Haendler, and Flavia Adani. 2014. "Accessibility effects through contrasts in the development of referential choices in German". Poster presented at the RefNet Workshop on Psychological and Computational Models of Reference Comprehension and Production, in Edinburgh.

Stickles, Elise. 2013. "Focus constructions in ASL: Evidence from pseudoclefting and doubling”. University of Pennsylvania Working Papers in Linguistics 19 (24).

Wilbur, Ronnie. 1996. "Evidence for the function and structure of wh-clefts in American Sign Language”. International Review of Sign Linguistics 1 (1): 209-256. 